\title{
Um Jogo Digital Baseado no Construcionismo
}

\author{
A Digital Game Based on Constructionism
}

\section{Carlos A. C. Lessa Filho}

Modelagem Computacional do Conhecimento

Instituto de Computação

Universidade Federal de Alagoas

carloswgama@gmail.com

\section{Fabio P. D. da Costa}

Modelagem Computacional do Conhecimento

Instituto de Computação

Universidade Federal de Alagoas

fabioparagua2000@gmail.com
Arturo Hernández Dominguez

Modelagem Computacional do Conhecimento

Instituto de Computação

Universidade Federal de Alagoas

arturohd@ic.ufal.br

Patrícia V. T. de A. Oliveira

Centro Universitário CESMAC

pattyvirginia@hotmail.com

Resumo Este artigo tem como objetivo apresentar o Sim Investigador, um jogo educativo baseado no construcionismo, desenvolvido para estudantes do ensino fundamental e médio. No jogo o estudante assumirá o papel de um investigador em um mundo fictício, no qual poderá adquirir o conhecimento construindo histórias no contexto de um conteúdo programático proposto por um professor, ou através da resolução de uma história já construída anteriormente por outro usuário. $O$ estudo de caso realizado com 49 estudantes do ensino fundamental revela resultados satisfatórios, de forma que a maioria dos estudantes manifestou que se sentia mais motivada aos estudos com o uso do jogo Sim Investigador.

Palavras-Chave: jogos educacionais, construcionismo, educação a distância

\begin{abstract}
This paper aims to present Sim Investigator, an educational game based on constructionism, for students in elementary and secondary education. In the game the student will be an investigator in a fictional world and he will can acquire the knowledge by constructing stories in the context of a curriculum proposed by a teacher or by resolution of a story previously made by another user. The case study conducted with 49 elementary school students reveals satisfactory results, because of most of the students expressed that he felt more motivated to studies using the Sim Investigador game.
\end{abstract}

Keywords: educational games, constructionism, distance education 


\section{Introdução}

Desde a década de 90, o Ministério da Educação trabalha com o sistema de Levantamento da Situação Escolar (LSE). Este método verifica as condições de funcionamento e desempenho das escolas da rede pública da educação básica. Os resultados dos últimos anos das principais avaliações revelaram uma generalizante preocupação em relação à qualidade da educação por parte dos envolvidos, desde educadores e governo até empresários e artistas, pois todos se sentiam incomodados com o precário desempenho dos alunos ao chegar nas universidades [1].

Segundo estatísticas [1], o problema de acesso a educação básica obrigatória praticamente já foi resolvido, sendo o real problema não a ampliação do número de escolas, mas a qualidade de ensino. Este problema não é uma novidade, uma vez que em 2005, Schwartzman [2] já informava que o Governo tentava resolver o problema da educação investindo na construção de novas escolas, quando o real problema se encontrava na qualidade de ensino dos estudantes, muitas vezes completando o ensino sem demonstrar preparo para assumir as suas funções na sociedade.

Segundo Longaray, Behar e Longhi [3], para Piaget o lado afetivo e o cognitivo (conhecimento) são considerados inseparáveis, pois sem o afetivo, que envolve as emoções primárias, secundárias e o estado de ânimo, o conhecimento nunca irá desenvolver-se por completo. Desta forma, é necessário ter interesse e sentir-se motivado, que serão responsáveis por impulsionar a busca de novos conhecimentos através de perguntas.

Por outro lado, o construcionismo de Seymour Papert [4] defende o pensamento que, para obter o real conhecimento sobre um determinado assunto é necessário realizar um procedimento de construção, em que o computador se torna um importante recurso para a criação de um material concreto do que se está sendo estudado. Além da importância do uso de computadores, também foi observado por Papert e Harel [4] a relutância que uma criança exerce ao ter que aprender o que será ensinado na escola, ao contrário do que ocorre nos conteúdos que são transmitidos pelos jogos da Nintendo. Pode-se entender a partir desta análise a importância do uso do lúdico no processo de ensino e aprendizagem. Para exemplificar este contato entre estudante e o lúdico pode-se citar a linguagem Logo, onde um estudante poderá aprender matemática construindo formas geométricas ao mesmo tempo em que controla uma tartaruga.

O uso do computador no processo de ensino no Brasil teve início na década de 70, na Universidade Federal de São Carlos, São Paulo, no ensino de Física. O computador como uma ferramenta de ensino ganhou força com a linguagem Logo e os trabalhos de Seymour Papert na década de 80 . Com as constantes mudanças realizadas durante esta evolução, passou-se a observar que o computador não deveria ser apenas instalado nas escolas, mas ter a sua importância reformulada (passar a utilizar o computador como uma ferramenta que auxilie o professor nas suas diversas atividades como docente). Desta forma, o professor não teria mais o papel de "entregador" do conhecimento, mas sim um facilitador; enquanto o estudante deixaria de ser passivo, para ter um papel importante no desenvolvimento do seu conhecimento [5].

Segundo César Coll et al [6] a educação não é dita como algo terminado, mas sim algo que ainda precisa ser construído e produzido. E neste processo educativo o professor irá agir como um mediador para auxiliar o estudante a construir o conhecimento. $\mathrm{O}$ professor tendo o papel de auxiliar a construção do conhecimento significa dizer que o aluno é o centro do processo educativo, com papel ativo, aprendendo a aprender, através das informações ministradas pelo professor em múltiplas situações, como visitas, leituras, explicações, entre outras.

Observando as dificuldades existentes nos métodos de ensino adotados nas escolas, este trabalho tem como objetivo apresentar um jogo construcionista que possa auxiliar ao professor e motivar os estudantes, através da criação de narrativas contextualizando os conteúdos ministrados.

\section{Reflexões sobre o construcionismo}

Para entender as ideias envolvendo o construcionismo de Seymour Papert, primeiro é necessário entender a ideia do construtivismo criado por Jean Piaget, que serviu como base para o construcionismo.

\subsection{Construtivismo}

Antigamente, a origem do conhecimento era considerada através do meio Apriorista, no qual o conhecimento ocorre por meio de ideias inatas que emergem do sujeito em processo de reminiscência; ou através do meio Empirista, no qual o sujeito nasce como uma tabula rasa, sem nenhum conhecimento e todo o conhecimento que é adquirido ocorre a partir da experiência com o meio [7].

No apriorismo, todo o conhecimento despertado é de único mérito e responsabilidade do sujeito, uma vez que ele já possuía este conhecimento e o professor teria apenas o papel de ajudar o estudante a desperta-lo. Já na visão do empirismo ocorre o contrário, em que podemos observar uma supervalorização no papel do professor, revelando um aprendizado behaviorista ou comportamentalista, onde todo o conhecimento desenvolvido pelo estudante seria de responsabilidade única do professor e 
do meio. Sendo assim, considera a ideia de que o professor teria a capacidade de formar ótimos ou péssimos profissionais como desejasse, desde que possuísse os recursos necessários.

Jean Piaget apresentou uma nova forma de se analisar a origem do conhecimento, em que não mais seriam analisados exclusivamente o sujeito ou o meio como fontes do conhecimento, mas uma visão biológica do ser, que teria a capacidade de adquirir novos conhecimento ao atingir certa faixa etária. Os quatros estágios do desenvolvimento do conhecimento podem ser organizados da seguinte forma $[8,9]$ :

- Sensório-motor - Ocorrendo do nascimento até aproximadamente os dois anos, é nesta fase que a criança começa a ter a noção do mundo através da manipulação. O conhecimento será adquirido através dos toques, movimentos, segurando e sentindo objetos.

- Pré-operatório - Inicia na transição dos dois anos até aproximadamente os sete anos. É nesta fase onde se inicia o desenvolvimento da linguagem e da escrita, aceleração dos pensamentos e sentimentos interindividuais. Garcia [9] informa que esta fase o conhecimento é voltada a intuição, ou seja, uma criança não consegue distinguir conceitos de peso, o que significa que dois objetos do mesmo tamanho não poderiam ter pesos diferentes.

- Operações Concretas - Ocorre por volta dos sete anos aos onze anos. É nesta fase onde se inicia o uso de raciocínio lógico e a capacidade de ter mais de um ponto de vista para uma situação. Nesta fase também começa o entendimento de operações concretas, como tempo, espaço e velocidade, possibilitando realizar operações reversíveis.

- Operações formais - Inicia por volta dos doze anos. No último estágio do desenvolvimento do conhecimento, o sujeito já possui um pensamento lógico num nível maior de equilibração, considerado por Piaget o auge do desenvolvimento cognitivo. O sujeito agora é capaz de realizar pensamentos abstratos e metáforas como "Quem tem boca vai a Roma". Nesta fase também é observado um aspecto antissocial, onde o sujeito se afasta mais das pessoas e rejeita conselhos, para realizar uma própria reflexão.

Ao longo dessas fases do desenvolvimento do conhecimento, o sujeito vai passando por mudanças que podem ser consideradas adaptação, onde sairá de um momento de desequilíbrio para um momento estável e equilibrado. Essa adaptação é composta por uma acomodação e uma assimilação, aplicando os novos esquemas aprendidos à realidade $[10]$.

\subsection{Construcionismo}

Papert possuía uma visão diferente de Piaget, que é apresentada no Construcionismo, na qual para gerar um conhecimento o sujeito deve construir algo concreto, ao contrário das formas abstratas e intangíveis de ensino.

Neste contexto, o sujeito desenvolverá novos conhecimentos através da construção. Esse processo estabelecerá uma relação entre o concreto e o abstrato por meio de reflexões, onde o sujeito poderá testar suas ideias, teorias e hipóteses. Enquanto realiza os seus testes, o sujeito buscará novos conhecimentos e analisará os erros, que não mais terão o papel de punição, pois agora eles auxiliarão na aprendizagem, uma vez que será necessário compreender os equívocos cometidos para que possa reformular seu processo de reflexão e depuração para que se chegue ao resultado desejado [11]. Assim, por ter uma visão real de como o conteúdo ministrado funciona, conseguirá obter um conhecimento completo do conteúdo como Papert defendia.

Durante um encontro realizado pela Pontifícia Universidade Católica na década de 80 , Papert e Paulo Freire puderam debater sobre as novas tecnologias e o futuro das escolas [12]. No encontro, Papert informa que existe uma quebra no aprendizado da criança no segundo estágio de aprendizagem, quando ela começa a ir à escola. Isto ocorre devido à criança não ser mais motivada a buscar ou a construir o conhecimento, passando apenas a receber o conhecimento ministrado pelo professor.

Para Papert a escola possui um aspecto negativo na vida do estudante, a partir do momento em que transmite os conteúdos programáticos de forma teórica, sem vivenciar o que está sendo estudado. Desta forma, o estudante não irá adquirir o conhecimento completo sobre o assunto, pois para obtê-lo é necessário o processo de uma construção. Um exemplo de uma construção por parte do estudante poderia ser uma elaboração de uma palestra, pintar um quadro, criar uma peça teatral ou desenvolver um programa de computador.

Atualmente já podemos perceber o uso do construcionismo presente em alguns colégios, como é o caso do uso da robótica, onde os estudantes do ensino fundamental criam seus robôs utilizando algumas plataformas abertas como o ARDUINO em competições ou eventos, como é o caso da Mostra Nacional de Robótica (MNR) [13].

É neste ponto onde o uso do computador na educação ganha espaço importante. Os computadores são ferramentas que permitem a construção de objetos com mais facilidade. Na linguagem Logo [14], usada com bastante frequência no Construcionismo, o usuário terá o controle de uma tartaruga que deixa rastros à medida que navega 
pela tela formando figuras geométricas, incentivando a criatividade e a busca de novos conhecimentos. Neste momento as crianças passavam a dar ordens ao computador e a programar, coisa que antes era apenas destinado a adultos.

Porém, o uso do computador nem sempre possui uma característica Construcionista. O computador também pode ser utilizado como uma forma de seguir instruções já definidas, tendo papel instrucionista [11]. Os softwares tutoriais são um clássico exemplo disto, pois os usuários não poderão questionar as ações, apenas executá-las, deixando de lado o papel de construção.

\section{Jogos Educativos}

Antigamente os jogos eram apenas vistos como atividades para serem realizadas no intervalo ou nas aulas de Educação Física, no entanto, segundo Fernandes [15], os jogos educativos podem ser aplicados em qualquer disciplina, de forma que os professores possam aplicar jogos em sala de aula para que os estudantes aprendam de forma mais prazerosa, usando um recurso de seu cotidiano.

A demonstração de uma disciplina usando recursos do cotidiano pode ajudar na assimilação dos conteúdos das disciplinas ministradas pelos professores. Este método é utilizado com crianças onde se explica a subtração na matemática através do repartimento de maçãs. É um modo diferenciado e divertido para exemplificar o que é visto na disciplina.

A dinâmica "Lidar com Pessoas Difíceis" em gerência de equipes de projetos de software [16] é um jogo não eletrônico onde um grupo de estudantes simula uma reunião de um projeto de software, no qual um dos estudantes assumirá o papel de gerente, enquanto os demais assumirão o papel de algum membro com personalidades difíceis, como reclamar de tudo. Por meio desses tipos de jogos os estudantes podem aprender, na prática, como resolver determinadas situações de forma mais dinâmica e didática.

\subsection{Jogos educativos digitais}

A vantagem dos jogos educativos digitais em comparação aos jogos educativos não digitais é a maior praticidade para realizar as demonstrações dos conteúdos de forma didática e lúdica. Segundo Grübel e Bez [17], a união entre computador e jogos educativos possibilita o aprendizado, como também o Ensino a Distância (EaD), de forma que o professor, mesmo sem a presença física, tenha condições de levar o estudante a construir seus conhecimentos através da interação com a máquina em diferentes situações, e até mesmo acompanhar o rendimento de seus estudantes.
O jogo "Where in the world is Carmen Sandiego?" [18] foi lançado em 1983 e obteve de forma rápida grandes fãs entre professores, pais e estudantes por incentivar o jogador a aprender geografia, história e matemática. Nele, o jogador deveria usar seus conhecimentos aprendidos no colégio para viajar pelo mundo em busca da ladra Carmen Sandiego. Mais de 300 mil escolas dos Estados Unidos utilizaram o jogo em sua grade curricular e o jogo obteve mais de 90 prêmios educacionais.

Os jogos educativos também podem ter uma função mais séria, como é o caso de MoviLetrando [19] que é um tipo de jogo considerado Jogo Sério. Jogo Sério é um jogo com uma finalidade maior do que o entretenimento, o objetivo é de transmitir um conteúdo educativo ao usuário. MoviLetrando possui como objetivo contribuir com os primeiros passos de letramento de crianças com Síndrome de Down. O jogo funciona usando uma webcam e um computador, de forma que as crianças deverão tocar nos símbolos que correspondem às letras solicitadas.

A atração de um jogo, segundo Clua e Bittencourt [20], normalmente está atrelada ao desafio imposto por ele. Seu funcionamento será governado através de um conjunto de regras, que definem o que os jogadores podem fazer e o que eles não podem realizar dentro desse mundo virtual. Durante a aprendizagem baseada em jogos digitais, os jogadores assimilam as informações e tomam decisões rapidamente, o que auxiliam a deduzir quais são as regras do jogo [21].

Os motores de jogos são uma peça importante no desenvolvimento de jogos digitais. Um motor de jogo possui uma arquitetura de software que possibilita a interligação de um conjunto de componentes [22]. Os principais componentes associados a um motor de um jogo são [22]: interação, visualização, áudio, interconexão em rede, física e inteligência artificial.

\subsection{Construção de jogos educativos digitais}

Além dos pontos abordados sobre jogos digitais vistos na subseção anterior, é possível observar que os jogos analisados, assim como a maioria dos jogos educativos, são focados em um tema específico, o que dificulta o seu uso em diferentes disciplinas ou conteúdos. Dessa forma, o professor ou estudante precisarão criar seus próprios jogos para atender a suas necessidades.

Para suprir essas necessidades, os professores poderiam realizar o desenvolvimento de um jogo por meio de kits que já possuem recursos prontos para o desenvolvimento de jogos. Alguns desses kits são:

- Unity - Criada pelo Unity Technologies é uma poderosa ferramenta para construção de jogos $3 \mathrm{D}$ e 2D [23].

- GameMaker - GameMaker Studio foi uma 
ferramenta desenvolvida pela YoYo Games com o intuito de desenvolver um kit capaz de atender tanto profissionais quanto pessoas sem conhecimento de programação [24].

- RPG Maker - RPG Maker é uma ferramenta fácil e intuitiva, com foco em jogos de turno, conhecidos como Role Playing Games [25].

Embora estes kits facilitem a construção de um jogo, para pessoas que não sejam profissionais da área ainda é necessário um bom conhecimento em informática para seu desenvolvimento.

Também é possível o uso de ferramentas de autoria multimídia que possibilitam o desenvolvimento de software educacional, tais como os jogos educativos digitais, com recursos de imagens, texto, vídeos e sons [26]. Podemos citar algumas dessas ferramentas: Visual Class, Adobe Director e Multimedia ToolBook.

\section{Trabalhos relacionados}

Os jogos construcionistas, ao contrário dos jogos educativos digitais comuns apresentados na seção 3.1, possuem uma maior liberdade de como o usuário irá tomar suas decisões, o que possibilita uma reflexão mais profunda de como trabalhar o que está sendo desenvolvido. Alguns jogos construcionistas podem ser observados nesta seção.

Sim City [27] é um jogo de simulação desenvolvido para computadores e vídeo games pelo estúdio de jogos Maxis. Sim City é a recriação do simulador de construção de uma cidade, onde o jogador terá como missão construir sua própria cidade, de forma que a cada ação realizada pelo jogador, resultará em uma reação na cidade, região ou até mesmo no mundo do jogo. Desta forma, o jogador será remetido várias vezes as diversas reflexões de como administrá-la e será capaz de aprender com os erros. Embora se trate de um jogo bastante conhecido, Sim City foi desenvolvido para o comércio de jogos, o que dificulta bastante o seu uso para o aprendizado em salas de aula, uma vez que é necessário comprar o jogo para usá-lo.

Outro jogo construcionista é o SPARSE [28], um jogo voltado ao ensino e aprendizado de Engenharia de Software. O jogo simula a construção e gerenciamento de um projeto envolvendo os elementos essenciais do desenvolvimento de um projeto, tal como as fases pelas quais esse projeto passará, com uma vasta variedade de formas de administrá-los. O jogo apresenta uma boa proposta no contexto de Engenharia de Software, tendo como projetos futuros a visão de adicionar recursos $3 \mathrm{D}$. Um ponto observado foi a ausência do recurso para a web, que poderia ser integrada para alcançar mais usuários e facilitar seu uso no contexto da Educação a Distância $(\mathrm{EaD})$.

\section{Um jogo baseado no construcionis- mo: Sim Investigador}

Como vimos na seção 2.2 desse artigo, no construcionismo o estudante tem o papel ativo durante o processo de aprendizagem e o professor terá o papel de ser um mediador para que o estudante alcance esse conhecimento por meio da construção de algo concreto relacionado ao conteúdo. No Sim Investigador essa construção será uma história sobre o conteúdo que outros jogadores possam jogar.

Nesta seção será apresentado o jogo proposto Sim Investigador (Figura 1) que pode ser acessado através do endereço www.siminvestigador.com.br. A linguagem utilizada no desenvolvimento do jogo foi o PHP, banco de dados MySQL, HTML e CSS que possibilitaram a construção de páginas dinâmicas para os usuários.

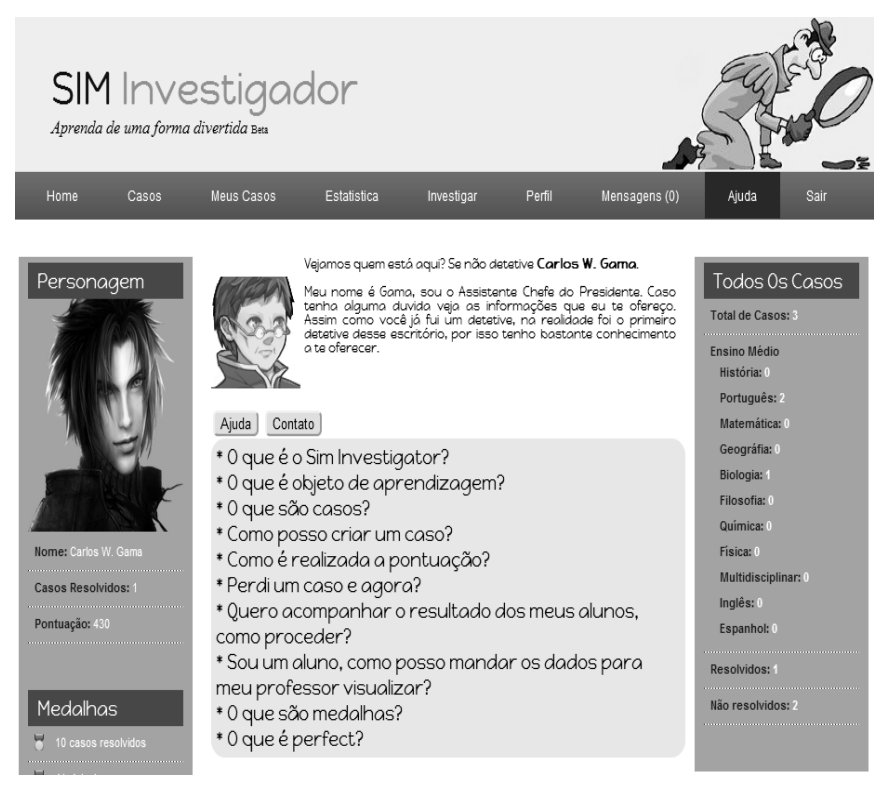

Figura 1: Visão Geral do jogo Sim Investigador

Baseado no jogo Where in the world is carmen sandiego, em Sim Investigador o jogador será envolvido num ambiente onde irá assumir o papel de um investigador, originando deste ponto o nome do jogo: Sim (Simulação) e Investigador (papel do personagem).

O estudante poderá aprofundar seu conhecimento sobre um conteúdo utilizando o Sim Investigador através de duas formas.

A primeira forma que o estudante pode aprofundar seu conhecimento é através da construção de casos, que são narrações que contextualizam um assunto no universo do jogo. O professor poderá solicitar aos seus estudantes que desenvolvam uma narração (caso) envolvendo um conteúdo ministrado em sala de aula. Desta forma, similar a construção de uma peça de teatro envolvendo o 
conteúdo sugerido pelo professor, os estudantes deverão realizar pesquisas sobre o conteúdo e quando necessário consultar ajuda dos professores, para que possam se aprofundar mais no assunto. Esse assunto deverá ser bem entendido pelos estudantes que irão construir a história, para que possam apresentá-lo em forma de casos jogáveis dentro do Sim Investigador. Além da narração e enredo, o usuário construtor do caso deverá preocupar-se em fazer com que o usuário que estiver jogando participe da narração da história, na qual para solucionar o caso necessitará responder perguntas sobre o assunto proposto. Assim, o usuário criador do caso, ao final desta etapa, terá passado por um processo de aprofundamento no conteúdo estudado para obter o conhecimento necessário para a contextualização da narração, e ao mesmo tempo será capaz de criar questões interessantes e pertinentes ao assunto para os demais usuários que irão interagir com o caso.

A segunda forma que o jogador pode se aprofundar sobre um determinado conteúdo é através dos casos já criados por outros usuários. Ao optar resolver um caso (papel de investigador), o usuário será envolvido na narração deste caso onde irá interagir na história resolvendo questões. Sendo assim, o usuário jogador do caso testará seus conhecimentos sobre o conteúdo abordado, podendo aprender com as explicações da narrativa ou realizar pesquisas para compreender qual a resposta correta para uma determinada pergunta. Quanto ao envolvimento do jogador dentro da história do caso, podemos dizer segundo Santos [29] que uma criança consegue aprender mais rapidamente vivenciando o objeto estudado.

Ainda de acordo com o envolvimento do jogador no universo do Sim Investigador, cada seção no Sim Investigador será representada por um personagem deste universo (Figura 2), explicando a usabilidade da seção aos usuários de uma forma lúdica.

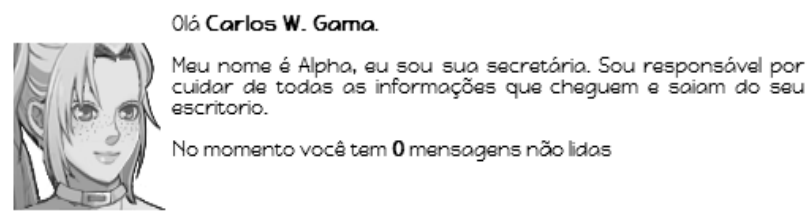

Figura 2: Personagem do jogo

Os menus no Sim Investigador apresentarão como padrão a estrutura da Figura 1. Do lado esquerdo serão listados os dados do usuário logado, como avatar, nome e pontuação. Do lado direito será apresentado um resumo de quantos casos existem por disciplina. Na parte superior, a navegação pelas diferentes seções (no Sim Investigador), e na parte central, as informações relacionadas a seção que o usuário está.

Entre as várias seções do jogo, como área de dúvidas, caixa de mensagem e estatísticas, podemos citar as duas principais: Casos e Meus Casos.
No menu Casos serão listados todos os casos já cadastrados e aprovados, informando quais desses foram finalizados ou não. Ao selecionar um caso, o usuário irá iniciar a história na qual deverá responder as questões sobre um conteúdo programático, contextualizadas no mundo do jogo.

Com características semelhantes à metodologia Problem-Based Learning $(\mathrm{PBL})^{1}$ [30], o usuário poderá aprender através de um problema real apresentado ao longo de cada história dos casos. Assim como, o desenvolvimento de um caso poderá ser motivado por um problema ou dúvida que o usuário já tenha presenciado, de forma que contextualize o que se deseja estudar.

Os casos são divididos em fases, onde cada tela do jogo é considerada uma fase. À medida que o usuário avança para a próxima tela, considera-se que uma fase foi avançada.

A estrutura da página (Figura 3) na resolução de um caso é formada por:

- Título do caso - Nome do caso que o usuário estará jogando;

- Imagem de fundo (Opcional) - Esse fundo será a imagem na parte superior, acima da fala dos personagens. É usada para ilustrar um cenário de acordo com a criatividade do usuário;

- Rosto de personagem (Opcional) - Representa o rosto do personagem que estiver falando;

- Narração - Ou balão de fala do personagem. Neste campo serão exibidas informações em forma de texto ou fala de personagem;

- Alternativas (Opcional) - Serão listadas alternativas que o usuário deverá responder corretamente para avançar para a próxima fase;

- Fase - Este campo indicará a fase atual;

- Erros Permitidos - Uma barra que representa a quantidade de erros que cada usuário pode cometer no caso ao responder uma questão de múltiplaescolha; Caso o número de erros ultrapasse o limite, será dado Game Over e o jogador deverá iniciar novamente o caso;

- Botão avançar - O botão avançar permitirá ao usuário ir para a próxima fase.

${ }^{1} \mathrm{O}$ processo de aprendizagem na PBL ocorre colocando o estudante de frente a um problema real, sobre o domínio do que está sendo estudado, como um sujeito ativo na aprendizagem, com a finalidade de aprimorar seu raciocínio e habilidades de comunicação através de uma situação real. [30] 


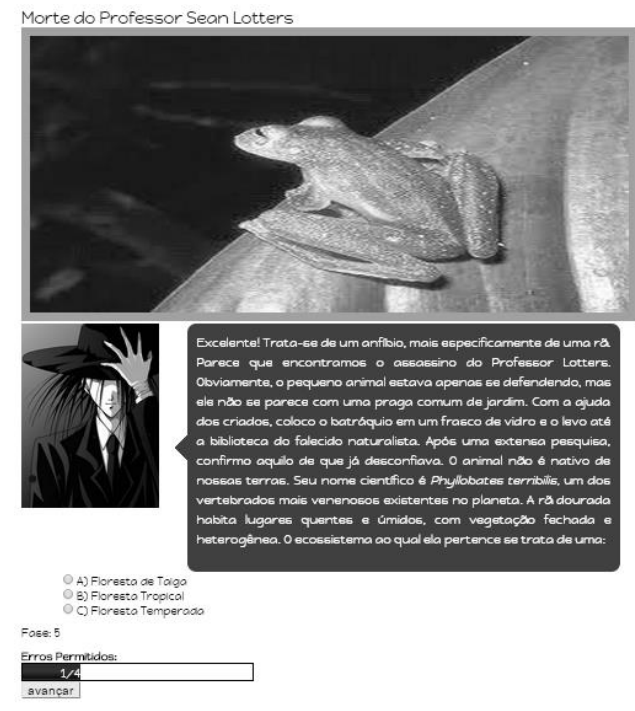

Figura 3: Estrutura de um caso

Ao final do caso, o jogador ganhará uma pontuação de acordo com o número de acertos e erros cometidos.

A seção Meus Casos será responsável pela construção de novas histórias dos usuários. Nessa seção o usuário poderá visualizar o status de suas histórias criadas ou em fase de construção, como pode ser observado na Figura 4. O caso pode se encontrar em uma das quatro situações abaixo:

- $\quad$ Rascunho - Status inicial de um caso em criação. Nesse status o criador do caso poderá fazer todas as modificações possíveis, como adicionar fases, escolher categoria, descrição, números de erros permitidos e título.

- Em avaliação - Após finalizar um rascunho, o caso entrará no status "Em avaliação". Após a avaliação de um professor ou administrador ele poderá ir para o status "Aprovado" ou "Reprovado".

- Aprovado - Nesse Status, o caso já está liberado para outros usuários jogarem.

- Reprovado - Se o caso apresentar conteúdo incoerente com a disciplina proposta poderá ser reprovado. $\mathrm{O}$ criador do caso poderá então realizar os ajustes e submeter novamente a avaliação.

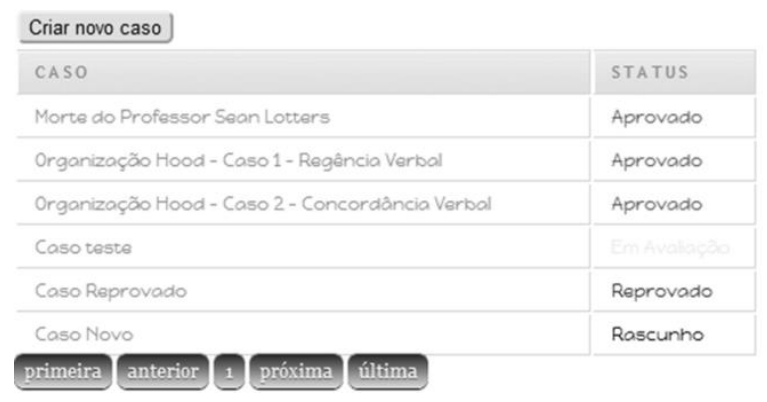

Figura 4: Status de um caso
A seção a seguir irá exemplificar um processo completo da criação e resolução de um caso para facilitar a compreensão dessas etapas.

\subsection{Exemplos de funcionamento do Sim In- vestigador}

Nesta seção serão apresentados três exemplos, no qual o primeiro irá apresentar a criação de um caso (seção 5.1.1); o segundo irá mostrar como um usuário pode jogar um caso criado (seção 5.1.2); e no ultimo (seção 5.1.3) será mostrado como o professor pode monitorar os resultados de seus alunos.

\subsubsection{Construção de casos}

Para exemplificar o uso do Sim Investigador em sala de aula, podemos citar uma situação em que o professor pede para que os seus estudantes criem uma história que deva explorar as características geográficas de cada região do Brasil.

Assim como ocorreria na construção de uma peça teatral, o primeiro passo do estudante será realizar pesquisas envolvendo informações relevantes sobre as diferentes regiões do país, pensar no enredo e refletir como o jogo funcionará.

Essas pesquisas podem ser realizadas em diferentes ambientes de acordo com a solicitação do professor. Se o professor deixar a pesquisa livre em qualquer ambiente, é interessante que os estudantes busquem em livros e na internet as informações desejadas sobre as regiões do Brasil. Ao encontrar uma dificuldade ou dúvida, poderão conversar com o professor, que ajudará os estudantes a compreenderem o conteúdo. Esta dúvida ou dificuldade poderá inclusive ser convertida para uma questão de múltipla escolha na construção do caso, de forma que a dificuldade do usuário criador venha a ser explicada e trabalhada também com o usuário jogador.

Após o estudante aprofundar-se no assunto sobre as Regiões do Brasil sugerido pelo professor e formular o enredo que deverá contextualizar o conteúdo, fazendo com que o usuário jogador do caso vivencie esta história, deverá então iniciar a construção do caso através da seção "Meus Casos".

Ao iniciar a construção, o usuário verá uma tela (Figura 5) onde poderá controlar todos os dados do seu caso. É nesta mesma tela em que poderá preencher as informações básicas da sua história como: o nome do caso; a categoria a qual ele pertence, podendo ser uma disciplina do ensino fundamental ou médio; o número de erros que um usuário poderá cometer ou deixar ilimitado o número de erros possíveis; e uma breve descrição que deverá informar o que a história irá abordar tanto no enredo, para que os demais usuários saibam do que se trata e qual o conteúdo programático que a história envolve. 

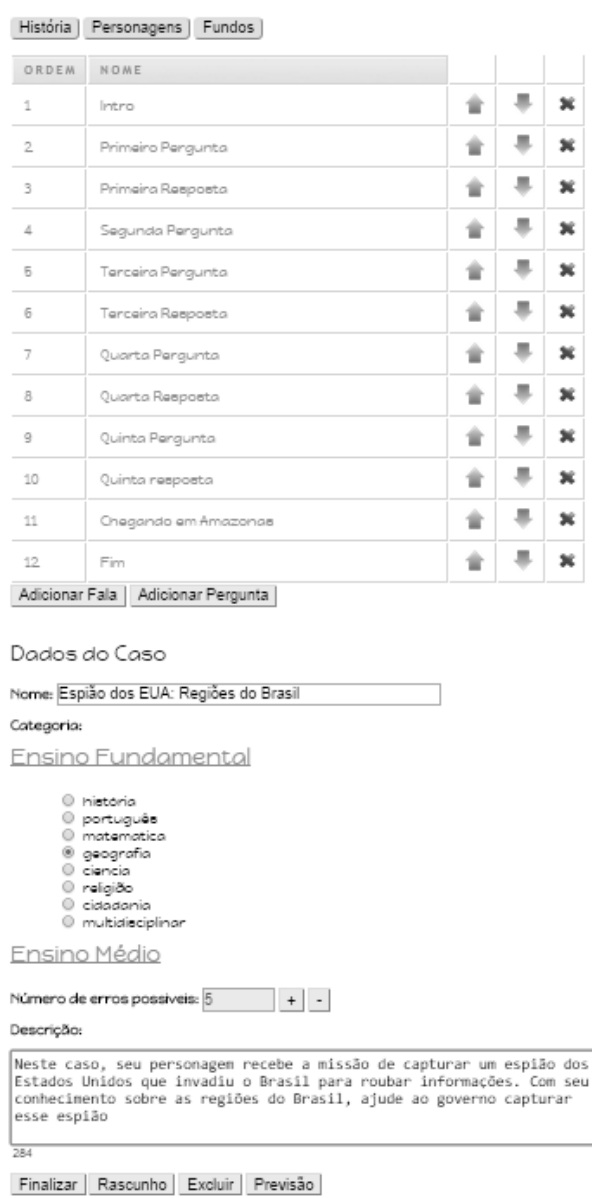

Figura 5: Construção de um caso - "Espião dos EUA: Regiões do Brasil"

Além das configurações básicas, através desta tela o usuário poderá navegar entre as opções "História", onde poderá adicionar as fases do jogo e dados do caso; "Personagens" para adicionar personagens; e "Fundo" para cadastrar as imagens de fundos que serão utilizadas no caso, como o mapa do Brasil.

Para cadastrar um novo personagem ou fundo (Figura 6), o processo será o mesmo. O usuário deverá informar um nome para a imagem e fazer um upload da imagem. Também poderá excluir personagens ou imagens cadastrados anteriormente. Recomenda-se que essas imagens possam trazer algum significado para as questões, como, por exemplo, a demonstração da resolução de um cálculo em um caso de matemática, ou a ilustração destacando um órgão no corpo humano em um caso de ciências ou biologia.

$\mathrm{Na}$ tela principal da construção do caso (História), o usuário poderá adicionar a fase através do "Adicionar Fala" ou "Adicionar Pergunta". A diferença de uma fase para a outra é que, em Adicionar Fala não há alternativas de múltipla-escolha para serem selecionadas ou não, enquanto em Adicionar Pergunta, além de preencher os dados como Nome da Fase, Narração, Fundo e Personagem, também será necessário adicionar alternativas de múltipla-escola (Figura 7).

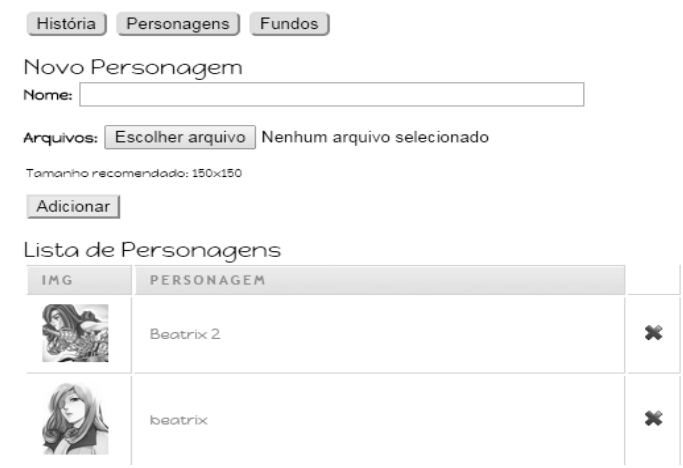

Figura 6: Cadastrando um personagem

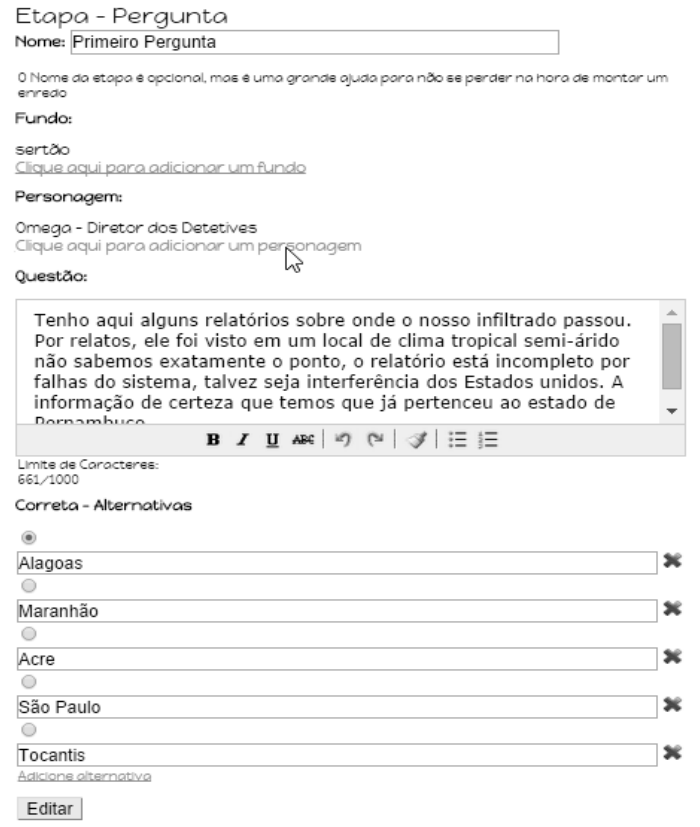

Figura 7: Adicionando uma Fase

Após adicionar todas as fases desejadas dentro do caso, contextualizando as características geográficas das diferentes regiões do país, o estudante poderá ver a previsão de como seria jogar o caso ou finalizá-lo (botões na parte inferior da Figura 5).

Ao finalizar a construção dos casos, o professor poderá visualizá-los através da área administrativa (Figura 8). A visualização funcionará da mesma forma como se estivesse resolvendo um caso. Assim o professor poderá avaliar o conteúdo construído pelo estudante, contextualizando as características das regiões brasileiras. 


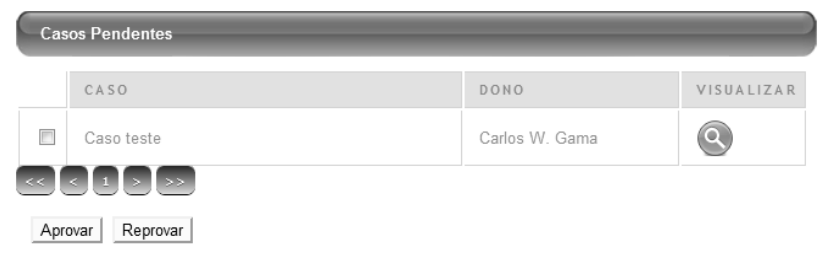

Figura 8: Área administrativa

$\mathrm{Na}$ ocorrência de uma reprovação de um caso, o professor deverá indicar ao estudante o que está errado sem explicar como resolver (Figura 9), para que o estudante volte ao processo de análise, reflexão e depuração.

\section{Casos Pendentes}

Casos:

\section{Espião dos EUA: Regiöes do Brasil}

Motivo

- Caso reprovado, verificar que as questões relacionadas a Região Sudeste não estão bem contextualizadas com as reais características dessa Região.

Figura 9: Reprovando um caso

Uma vez que o caso foi aprovado pelo professor avaliador, este permanece disponível para os demais usuários jogarem. Um professor ou usuário poderá visualizar a pontuação que um grupo de usuários ou todos os usuários conseguiram ao resolver o caso através da seção "Investigar" no menu, escolhendo o caso desejado. Nesta seção poderá visualizar a pontuação e a data da primeira vez que o usuário concluiu o caso com sucesso (Figura 10), como também filtrar os usuários por grupos, facilitando a busca pela informação dos usuários que se tem interesse.

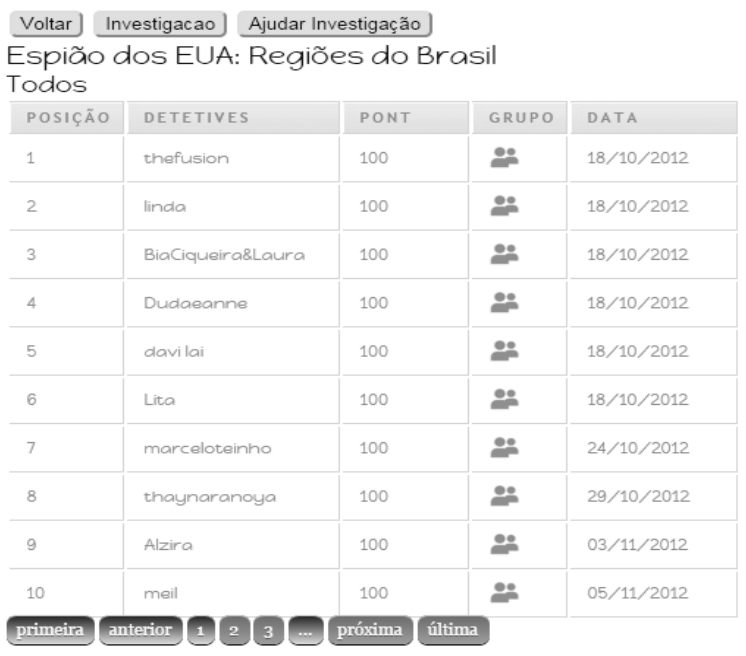

Figura 10: Pontuação dos usuários

\subsubsection{Jogando no Sim Investigador}

Além do aprendizado que pode ocorrer através da construção de histórias, como visto na seção anterior, o estudante também pode aprofundar o seu conhecimento jogando um caso criado, onde irá vivenciar e interagir com o objeto de estudo.

Seguindo o exemplo do professor que solicitou que os estudantes criassem uma história envolvendo as características das Regiões do Brasil, após esses estudantes terem finalizado a etapa de construção de uma história, o mesmo professor poderia solicitar que os estudantes desta classe jogassem os casos criados por seus colegas, com a finalidade deles conhecerem as informações das Regiões do Brasil que eles não exploraram durante a construção de suas próprias histórias.

Para isto, os estudantes após já terem se aprofundado no conhecimento estudado para a construção do caso, agora deverão acessar a seção de "Casos", onde serão listados todos os casos aprovados no sistema.

Os casos estarão separados de acordo com as disciplinas a qual eles pertencem, e classificados em "Resolvido" e "Não resolvido". Os casos resolvidos serão representados na cor verde e com um símbolo de Tick $(\sqrt{ })$. Os casos ainda não resolvidos serão representados pela cor cinza e com uma exclamação ao lado (Figura 11).

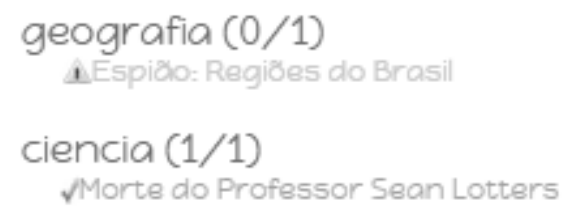

Figura 11: Exemplo de status dos casos

Os estudantes que não foram responsáveis pela construção do caso "Espião dos EUA: Regiões do Brasil", agora deverão resolver este caso clicando sobre o título dessa história. Desta forma, esses estudantes vão aprofundar seu conhecimento sobre as regiões do Brasil.

Ao iniciar um novo caso, será apresentada ao usuário jogador a primeira fase do caso. Cada tela do jogo representa uma fase, que poderá conter imagens, balões de diálogos, imagens do personagem que está falando, o número de erros permitidos e a opção de avançar, além das alternativas para quando existir uma pergunta.

Na primeira fase do caso "Espião dos EUA" (Figura 12) é apresentada ao jogador uma introdução. Assim, o estudante atuará como um investigador que recebeu a missão de capturar um espião que invadiu o Brasil: 


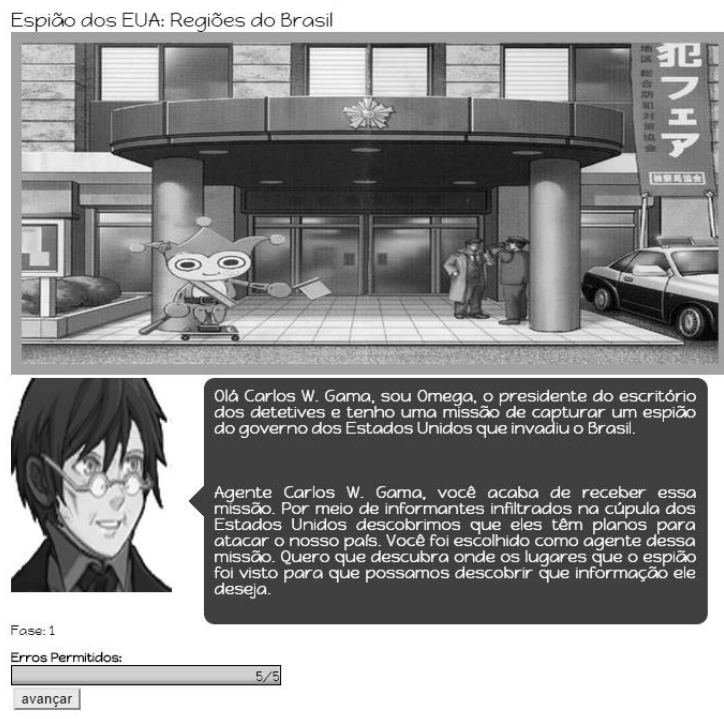

Figura 12: Fase introdutória

Seguindo para a próxima fase, o jogador irá se deparar com a primeira pergunta contextualizada em relação às Regiões no Brasil. Nesta nova tela (Figura 13) podemos observar a presença de alternativas, que obrigatoriamente precisarão ser respondidas corretamente para prosseguir com o caso. Um personagem na fase informa ao jogador que a última informação que tiveram do espião é que ele esteve em uma região de clima semiárido e em um estado que já fez parte de Pernambuco.

O usuário jogador agora poderá testar seus conhecimentos identificando em qual estado o espião foi visto, usando o seu conhecimento estudado para a criação de seu caso.

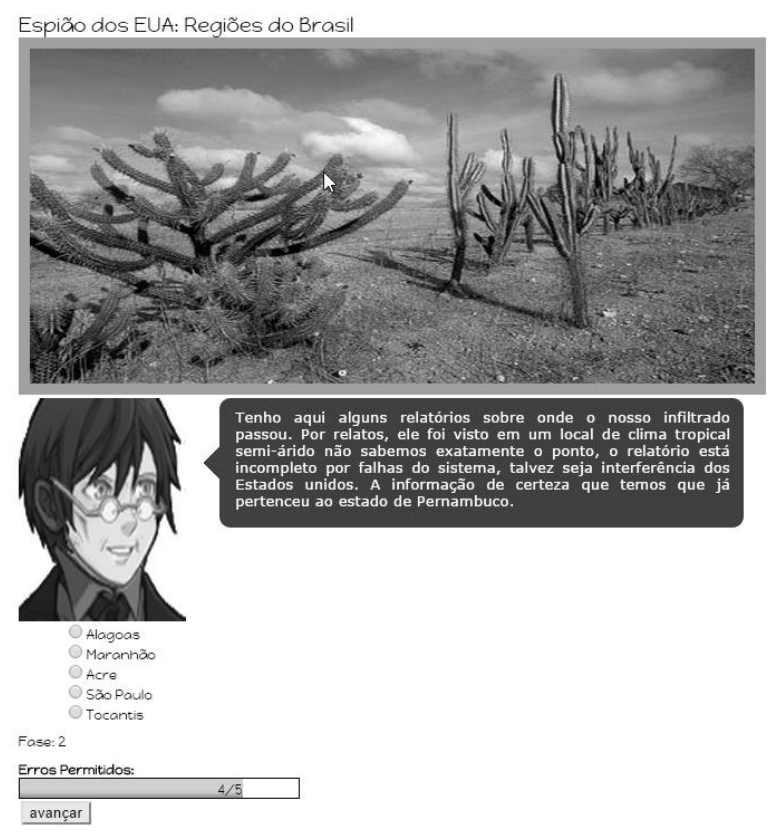

Figura 13: Primeira pergunta
Ao responder uma alternativa errada o jogador será informado que cometeu um erro (Figura 14) e poderá tentar novamente, enquanto a sua barra de erros permitidos não chegar a zero.

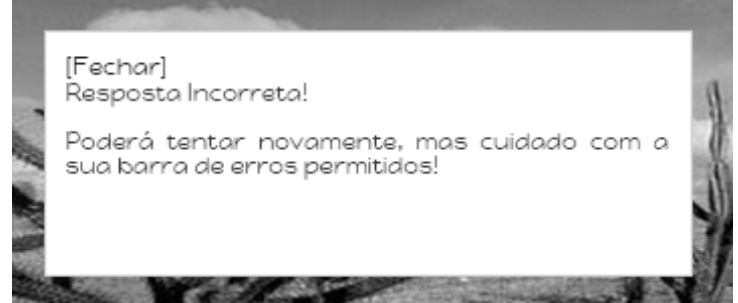

Figura 14: Falha na resposta

Quando a barra de erros chegar a zero, o caso será perdido (Figura 15). Neste momento é recomendado que o estudante realize novamente pesquisas ou busque o auxílio do professor e colegas para se aprofundar mais e ser capaz de completar o caso.

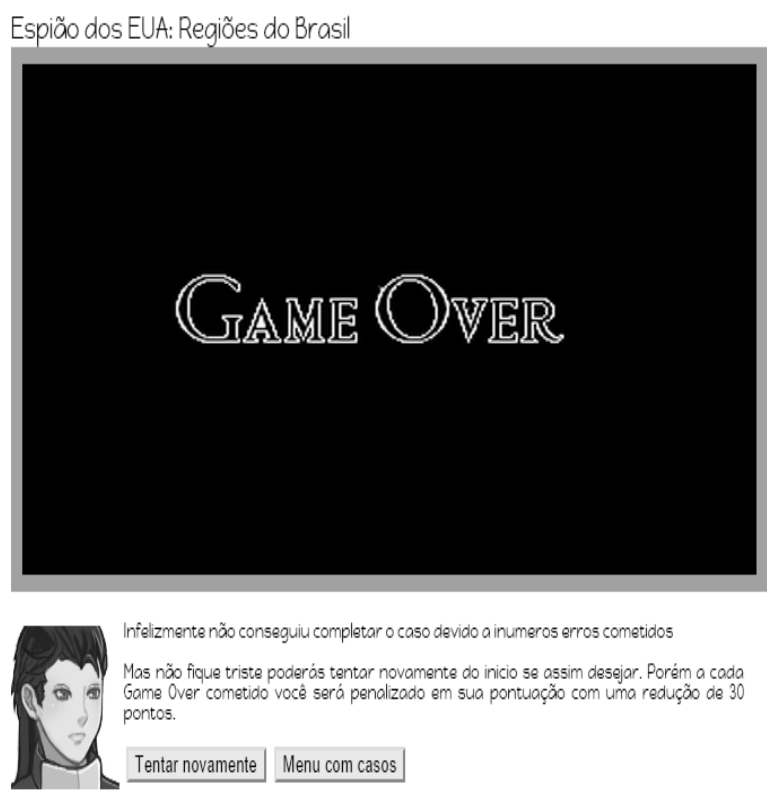

Figura 15: Game Over

Na ocasião do jogador acertar a alternativa correta, irá prosseguir para a próxima fase, em que será explicado o motivo da alternativa "Alagoas" estar correta e fazer uma conexão com a próxima fase (Figura 16). A vantagem de se explicar o motivo para a alternativa estar correta, é que mesmo que o jogador não tenha uma noção exata do motivo daquela ser a alternativa correta, com a explicação apresentada na fase seguinte, o jogador irá reforçar ou aprender fatos que não sabia sobre o estado de Alagoas. 


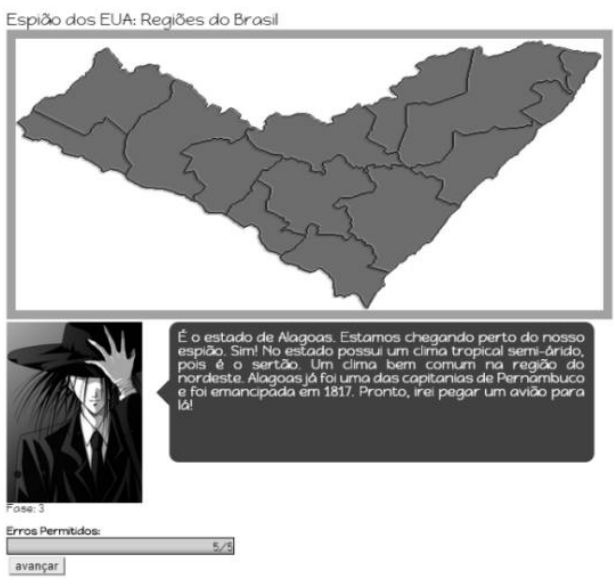

Figura 16: Resposta correta

Após completar todas as fases com sucesso, o usuário será apresentado a tela de Missão Concluída (Figura 17), no qual poderá observar a pontuação obtida, de forma que para cada resposta acertada na primeira alternativa, se obtém 10 pontos. Sendo assim, poderá avaliar seu desempenho e evoluções nas próximas jogadas.

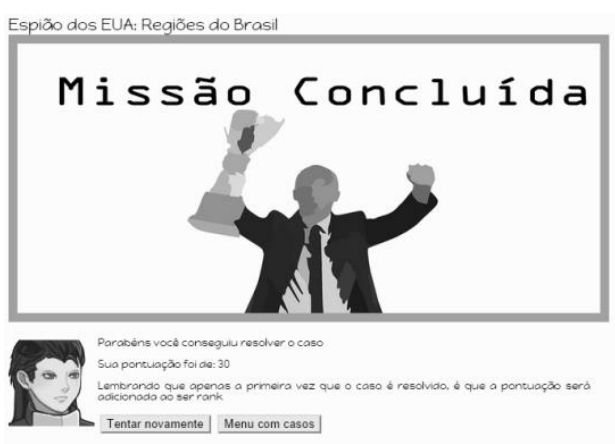

Figura 17: Missão Concluída

\subsubsection{Monitorando casos resolvidos}

O recurso "Investigar" pode ser utilizado pelos professores para monitorar o desempenho dos seus estudantes. Por tanto, após a etapa de construção e resolução de um caso, agora o professor poderá avaliar o desempenho de seus estudantes na resolução dos casos.

Através da opção "Investigar" no menu do topo, o professor poderá escolher investigar um caso criado, onde serão listados todos os usuários que já completaram o caso selecionado ou apenas os seus alunos.

Ao acessar um caso para investigar, o professor visualizará dois grupos fixos (Figura 18): "Todos", que listará todos os usuários do jogo Sim Investigador que já resolveram o caso selecionado; "Investigados", que é um recurso em que os estudantes podem enviar ao professor a sua informação da pontuação e data de conclusão (Figura 10) para que o professor não precise procurar pelos seus estudantes entre todos os usuários cadastrados no Sim Investigador.

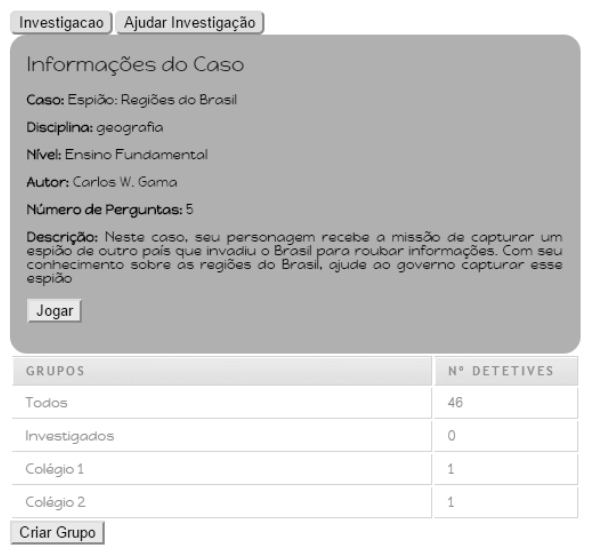

Figura 18: Monitorando resultado dos casos

$\mathrm{Na}$ ocasião de um professor ter diferentes colégios ou turmas, poderá criar grupos e definir a qual grupo um estudante pertence.

A partir destas informações, o professor poderá observar possíveis dificuldades dos seus estudantes sobre determinados assuntos e analisar qual melhor estratégia a seguir.

\subsection{Modelagem do Sim Investigador}

Nesta seção, a arquitetura de software (Figura 19) e o diagrama de classes do Sim Investigador (Figura 20) são apresentados. A notação UML [31] foi utilizada na modelagem desses artefatos. UML é uma linguagem unificada utilizada para modelar sistemas de software baseados no paradigma da orientação a objetos.

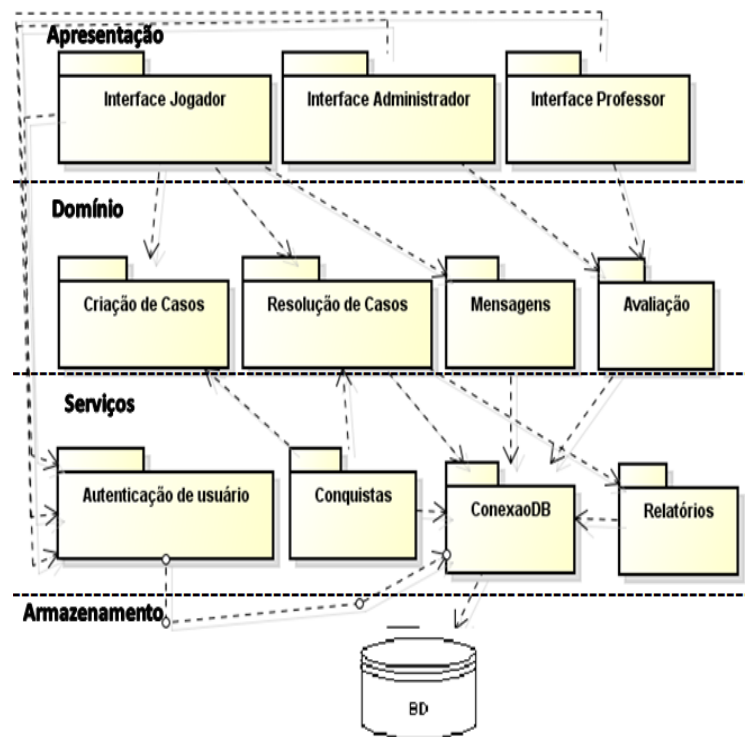

Figura 19: Arquitetura de Software do Sim Investigador 
$\mathrm{Na}$ camada de apresentação, podemos observar as diferentes interfaces que cada usuário do jogo Sim Investigador poderá visualizar. A interface do jogador é representada pelas telas aonde o jogador poderá criar e jogar os casos existentes. $\mathrm{Na}$ interface do administrador, o usuário poderá avaliar os casos em espera de avaliação, e gerenciar usuários e conteúdos vinculados aos casos. Para a interface do professor, esse subsistema será similar ao do administrador, apenas não podendo gerenciar os usuários do jogo.

Dentro da camada de domínio, podemos ver o subsistema de criação de casos, onde o usuário criador do caso deverá informar as disciplinas e fases que compõem o caso. No subsistema de resolução de um caso será representada a jogada ou partida do caso, onde o usuário obterá a pontuação de acordo com o seu desempenho. Já o subsistema de mensagens é responsável pela troca de mensagens entre os usuários. O subsistema de avaliação permitirá que professores e administradores avaliem o caso criado por um usuário, para aprová-lo ou reprová-lo.

Já na camada de serviços, podemos observar o subsistema responsável pela: autenticação do usuário; os relatórios gerados de acordo com a pontuação dos usuários e as medalhas obtidas pelos usuários como forma de conquistas por terem realizado determinadas ações, como concluir um caso; e a ConexaoDB, que é responsável por controlar as comunicações entre o banco de dados e os demais subsistemas.

Na camada de armazenamento fica o subsistema responsável pelo armazenamento das informações.

O diagrama de classes (Figura 20) apresenta as diversas classes associadas ao jogo Sim Investigador relacionadas a camada de domínio da arquitetura de software (Figura 18). As classes envolvidas na construção de casos são: Caso, Usuário, Fase, Fundo, Alternativa, Personagem, Disciplina. As classes envolvidas na resolução do caso são: Jogada, Caso, Usuário, Disciplina, Fase, Fundo, Alternativa, Personagem. As classes envolvidas nas mensagens entre usuários são: Mensagem e Usuário. E por último, as classes envolvidas no subsistema de Avaliação são: Avaliação, Caso, Disciplina, Fase, Fundo, Alternativa e Personagem.

Como pode ser observado pelo diagrama de classes da Figura 20, o sistema funciona em função da classe Caso, que será a principal responsável para as avaliações, jogadas e criação de casos.

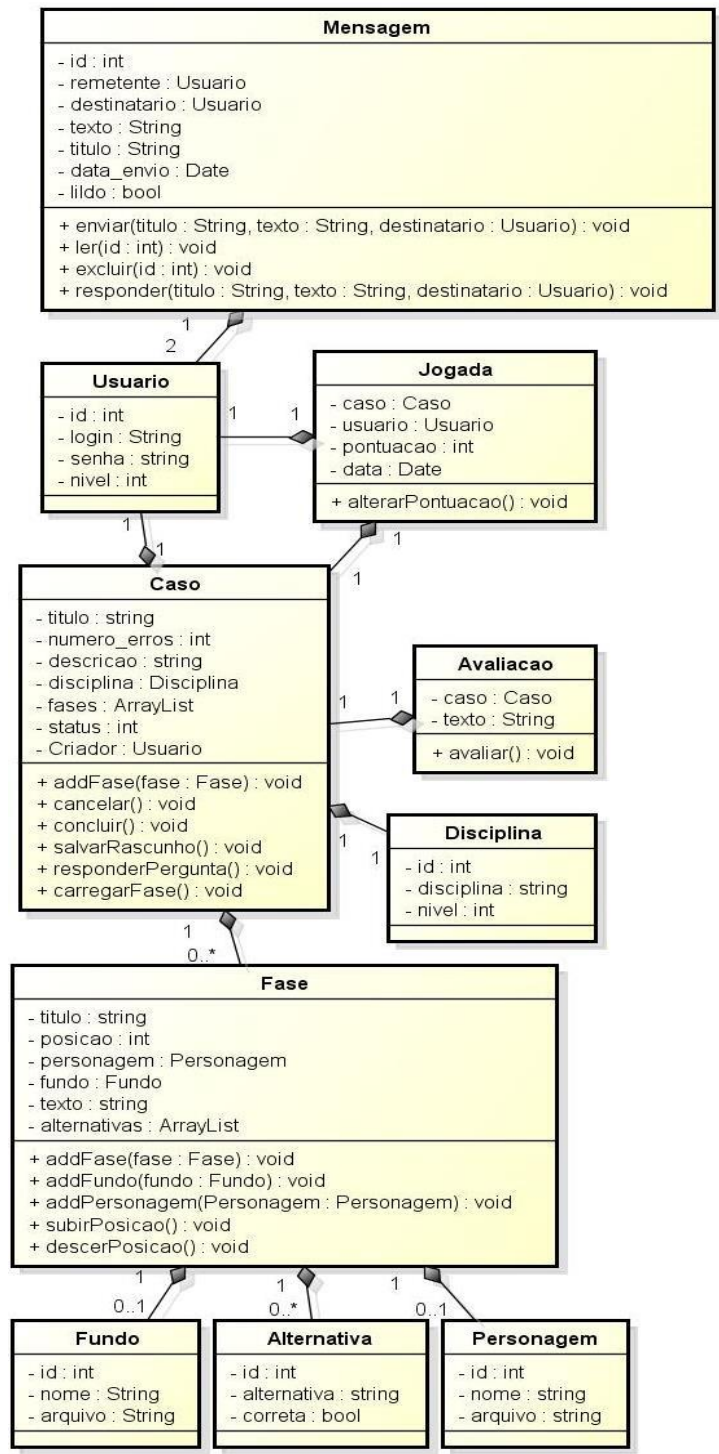

Figura 20: Diagrama de classes

\section{Estudo de Caso}

O estudo realizado com o jogo Sim Investigador buscou uma verificação sobre sua usabilidade, motivação e interesse por parte dos estudantes e professores. $\mathrm{Na}$ amostra do estudo participaram 49 estudantes do ensino fundamental de três turmas diferentes, sendo estes estudantes do sexto e nono ano do ensino fundamental e das instituições de ensino (Maceió/AL): Nossa Senhora do Amparo, Santíssimo Senhor e Maria Montessori. Foram realizadas tentativas de conciliar a participação dos professores dos alunos que envolviam as disciplinas dos casos, porém não foi possível devido a preocupação das coordenações em atrasar seus cronogramas e estudos dos estudantes, uma vez que seria necessário o estudo ocorrer 
no horário da aula do professor e não na disciplina de informática.

No contato estabelecido com os estudantes foi apresentada inicialmente a ideia do que é o jogo Sim Investigador e uma explicação das funcionalidades. Posteriormente a explicação inicial, foi solicitado aos estudantes que resolvessem um dos casos já criados previamente de acordo com o seu nível de escolaridade e disciplina, para compreender como funciona o jogo Sim Investigador. Entre os casos disponíveis estavam: Espião dos EUA: Regiões do Brasil (Geografia), Morte do Professor Sean Lotters (Ciências), Organização Hood - Caso 1 - Regência Verbal (Português), Organização Hood - Caso 2 Concordância Verbal (Português).

Enquanto os estudantes conheciam como a resolução de um caso funcionava, o professor foi convidado a observar a interação dos estudantes com o jogo.

Após solucionarem um ou mais casos, os estudantes foram apresentados a seção "Meus Casos", onde aprendiam a como construir suas próprias histórias. No final do encontro estudantes e professores respondiam um questionário, dentro da própria ferramenta, a respeito dos recursos apresentados, as impressões sobre o jogo, sugestões de melhorias e sobre o sistema atual de ensino. As perguntas relacionadas ao ensino tinham como finalidade entender melhor os problemas no ensino atual do Brasil, como o jogo pode influenciar o aprendizado e quais possíveis melhorias futuras no jogo.

As perguntas do questionário para estudantes e professores apresentam as mesmas categorias, sendo elas: Opinião sobre o ensino e Opinião sobre o jogo. Todavia, as perguntas divergem entre o questionário do professor e o questionário do estudante. O questionário foi desenvolvido em PHP aplicado via Web e disponibilizado ao usuário após jogar um caso.

Após a coleta foi realizada a análise dos resultados, utilizando a ferramenta estatística $\mathrm{R}$ para gerar gráficos possibilitando a visualização dos resultados obtidos.

\subsection{Resultados e Discussão}

Após obter os resultados dos questionários aplicados relacionados às opiniões sobre o ensino e o jogo Sim Investigador, pode-se constatar em relação às opiniões dos estudantes voltadas ao ensino que a maioria dos estudantes $(63 \%)$, ao contrário do que é visto na literatura, não consideram sentir dificuldades em aprender através de livros e explicações no quadro de forma abstrata (Figura 21); porém entre os estudantes que responderam que sentem dificuldade $(32 \%)$, pode-se observar que suas dificuldades estão vinculadas a não conseguirem assimilar o conteúdo da forma apresentada pelo professor.

Outro ponto questionado aos estudantes no contexto do ensino foi sobre o esquecimento precoce. Através dos resultados foi possível observar que $75 \%$ dos estudantes tendem a esquecer do que foi estudado no ano anterior, como pode ser constatado na literatura, demonstrando uma preocupação com a nota ao invés do aprendizado.
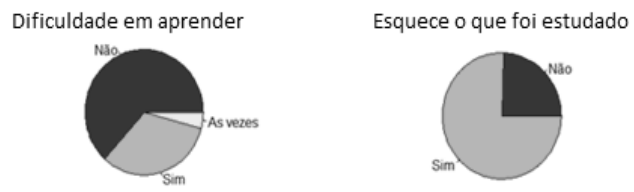

Figura 21: Dificuldades no ensino.

Outro fato relacionado ao ensino que surpreendeu foi quanto à motivação dos estudantes ao estudo (Figura 22). Apenas 11 dos 49 estudantes informaram que não se sentem motivados a estudar. Vários estudantes, 30, informaram se sentirem motivados, e 8 deles informaram que a motivação depende da disciplina ou professor. Todavia, os estudantes que informaram não se sentir motivados aos estudos, alegaram que os métodos de ensino eram sempre os mesmos, não variando, tornando o ensino cansativo e estressante.

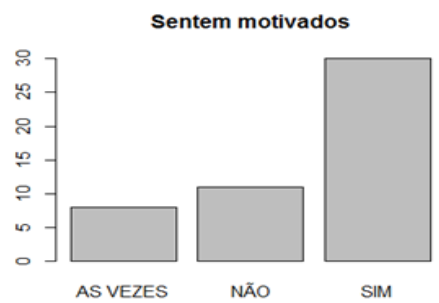

Figura 22: Motivação dos estudantes em relação ao estudo

Quanto aos professores em relação ao ensino, foi questionado sobre qual a maior dificuldade que eles encontram em apresentar o conteúdo para os estudantes. $\mathrm{O}$ resultado da pesquisa foi a falta de recursos diferenciados para se usar em sala de aula e a dificuldade em como cativar a atenção do estudante em aula.

Em relação aos questionamentos voltados ao jogo Sim Investigador e jogos educativos, pode-se observar que 34 dos 49 estudantes nunca tinham tido contato com jogos parecidos voltados a educação. Ao questionar se sentiam mais motivos aos estudos através dos jogos ou das aulas tradicionais, do total de estudantes, 38 informaram se sentir mais motivados aos estudos com a utilização do jogo Sim Investigador (Figura 23) e um estudante considerou interessante a ideia de se trabalhar o jogo unido às metodologias atuais usadas pelos professores, de forma que o jogo serviria para descontrair e ver exemplos, enquanto o professor auxiliaria ao tirar as dúvidas que os estudantes venham a ter no jogo através das aulas em sala. Em ambos os casos a presença do professor se torna indispensável, porém o baixo resultado relacionado a união do jogo e da aula tradicional, o que seria a melhor situação sobre o ponto de vista pedagógico, pode ser 
observado através das respostas dos estudantes que está relacionado com o fato de como a aula tradicional é ministrada, sendo comentado que as aulas tradicionais são menos interessantes e divertidas, e mais cansativas.

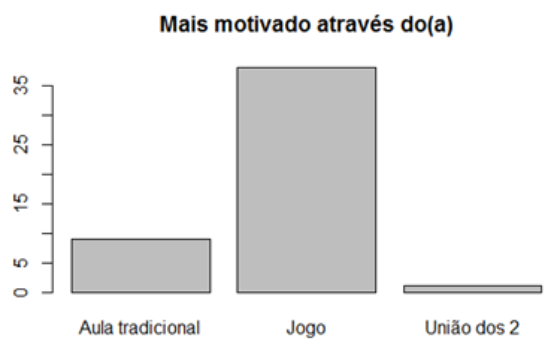

Figura 23: Motivação dos estudantes em relação ao jogo

Dentro do contexto da construção de histórias pelos próprios estudantes, verificou-se uma grande aceitação, representando 46 dos 49 estudantes. Estes informaram que gostaram da possibilidade do usuário poder construir suas próprias histórias no contexto de uma disciplina.

Em relação à construção de histórias pelos usuários, nas opiniões dos professores que participaram do questionário, todos concordaram com a ideia do usuário poder criar suas próprias histórias, sendo levantado o ponto de que mesmo sem um conhecimento profundo sobre o conteúdo, o estudante irá adquiri-lo à medida que irá desenvolvendo a história.

As últimas perguntas do questionário envolviam usabilidade, visual e melhorias no jogo Sim Investigador. Entre as opiniões foi constatada uma grande satisfação dos estudantes com o contato com o jogo, por ser uma novidade e forma divertida de aprender os conteúdos ministrados em sala de aula. Em relação às melhorias, pode-se observar o desejo dos estudantes quanto à possibilidade de ter menos texto e mais dinamismo, como controlar um personagem por um cenário. Por parte dos professores foi sugerido melhoria visual, para que possa agradar a jogadores mais novos.

\section{Conclusão}

As dificuldades de como motivar o estudante no processo de aprendizagem sempre foi um grande problema encontrado pelos professores e órgãos de ensino. Sendo apontado por estudos que a falta de interesse e motivação aos estudos ocasionam com frequência estudantes não aptos ao mercado de trabalho.

O jogo Sim Investigador tem como proposta possibilitar que o estudante aprofunde o seu conhecimento em um assunto através de construções de casos, que são histórias similares a uma peça teatral, onde o jogador fará parte do roteiro da história. Além do usuário criador do caso ter de se preocupar em compreender o conteúdo para apresentálo em uma narração, também haverá de se preocupar em criar questões que deverão ser respondidas por quem jogar o caso, possibilitando assim a interação entre o usuário jogador com o caso. $\mathrm{O}$ jogo também possibilita uma aprendizagem através da resolução dos casos criados, em que os jogadores necessitarão buscar o conhecimento através de pesquisas para estarem aptos a solucionar um caso.

Para verificação do jogo proposto foi aplicado o Sim Investigador em turmas diferentes com a finalidade de verificar o interesse e usabilidade do jogo. Foram analisados fatores relacionados ao ensino segundo a visão dos estudantes e professores. Os resultados obtidos revelaram que os estudantes demonstram sentir interesse pelos estudos, mas que ainda possuem algumas dificuldades como o esquecimento precoce. Em relação ao jogo Sim Investigador, foi possível observar, nos resultados, o interesse e a alta motivação no uso do jogo por parte dos professores e estudantes.

O jogo Sim Investigador apresentado neste trabalho representa uma iniciativa que possibilita melhorar a motivação dos alunos no processo de aprendizagem de um conteúdo no contexto de uma disciplina do ensino fundamental.

Como trabalhos futuros, deseja-se possibilitar a criação de histórias em ambientes 2D utilizando a engine Unity. Também o Sim Investigador será utilizado no contexto da disciplina de Engenharia de Software do curso de Ciência da Computação e Engenharia de Computação na Universidade Federal de Alagoas.

\section{Referências}

[1] J. R. Borges. Levantamento da situação escolar em sistemas municipais de ensino no Rio Grande do Sul: Uma determinação política de financiamento do ensino público e/ou ferramenta de gestão?. Rio Grande do Sul, Tese de doutorado na Universidade do Vale do Rio dos Sinos. 2014.

[2] S. Schwartzman. Os desafios da educação no Brasil. Rio de Janeiro, Nova Fronteira. 2005

[3] A. N. C. Longaray, P. A. Behar, M. T. Longhi. Afetividade em um ambiente virtual de aprendizagem: um estudo sobre os indicadores pedagógico. In Simpósio Brasileiro de Informática na Educação. 2012.

[4] S. Papert, I. Harel. Constructionism. Ablex Publishing Corporation. 1991

[5] Secretária de Educação a Distância. O computador na sociedade do conhecimento. Coleção informática para a mudança na Educação. 1999. 
[6] C. Coll, E. Martín, T. Mauri, M. Miras, J. Onrubia, I. Solé, A. Zabala. O construtivismo na sala de aula. São Paulo Ática, 2006.

[7] G. Rizzon. Investigação de Jean Piaget: A epistemologia genética e o apriorismo. Universidade de Caxias do Sul. 2009.

[8] D. S. Cardoso, M. C. C. Baranauskas. Um caderno digital nos laptops educacionais: proposta conceitual e ferramenta. Revista Brasileira de Informática na Educação, Volume 17, Número 2. 2009 .

[9] S. M. dos S. Garcia. A construção do conhecimento segundo Jean Piaget. Revista, volume 6, p.17-28.1998.

[10] J. O. C. Arias, A. P. Yera. O que é a pedagogia construtivista?. Revista Educação Publica, volume 5, número 8, Cuiabá, páginas.11-72. 1996.

[11] M. G. de Albuquerque. Um ambiente computacional para aprendizagem matemática baseado no modelo pedagógico de Maria Montessori. Universidade Federal de Santa Catarina. 2000

[12] S. Papert, P. Freire. The Future of School. http://www.papert.org/articles/freire/freirePart1. html. Acesso em 24 set. 2014.

[13] P. J. Silva, B. A. Moraes, V. Jordão. Corpo e Tecnologia: novos cenários para inclusão. Anais da I Mostra Nacional de Robótica. 2011.

[14] R. C. S. Camacho, C. Fino. Síntese Crítica ao livro de Seymour Papert "A Máquina das Crianças Repensando a escola na era da informática". Universidade da Madeira. 2010.

[15] J. C. L. Fernandes. Educação digital: Utilização dos jogos de computador como ferramenta de auxílio à aprendizagem. In Periódico Eletrônico da FATEC, volume 1, número 3, páginas 88-97. 2010.

[16] C. G. von Wangenheim, O. P. Carvalho, P. E. Battistella. Ensinar a Gerência de Equipes em Disciplinas de Gerência de Projetos de Software. In Revista Brasileira de Informática na Educação, Volume 21, Número 1. 2013.

[17] J. M. Grübel, M. R. Bez. Jogos Educativos. Renote, volume 4, número 2, página 1-7. 2006

[18] Carmen Sandiego. Where in the world is Carmen Sandiego?. Disponível em: http://www.hmhco.com/parents-and-kids/thelearning-company/carmen-sandiego/history. Acesso em: 24 set. 2014.
[19] E. H. Farias, M. da S. Hounsell, L. B. Blume, , F. R. Ott e F. V. P Cordovil. MoviLetrando: Jogo de Movimentos para Alfabetizar Crianças com Down. In Simpósio Brasileiro de Informática na Educação. 2013.

[20] E. W. G. Clua, J. R. Bittencourt. Uma Nova Concepção para a Criação de Jogos Educativos. In Minicurso do Simpósio Brasileiro de Informática na Educação. 2004.

[21] M. Prensky. Digital game-based learning. New York: McGraw-Hill. 2001.

[22] J.R. Bittencourt, F.S. Osório. Motores para Criação de Jogos Digitais: Gráficos, Áudio, Interação, Rede, Intelligência Artificial e Física. Disponível

em http://osorio.wait4.org/publications/BittencourtOsorio-ERI-MG2006.pdf

[23] Unity Technologies. Unity. 2014. Disponível em: http://unity3d.com/pt/unity, acesso em 24 set. 2014

[24] YoYo Games. GameMaker. 2014. Disponível em: https://www.yoyogames.com/studio, acesso em 24 set. 2014.

[25] RPG Maker. RPG Maker. 2014. Disponível em: http://www.rpgmakerweb.com, acesso em 24 set. 2014

[26] G. A. M. Falkembach, M. Geller, S. N. Silveira. Desenvolvimento de Jogos Educativos Digitais utilizando a Ferramenta de Autoria Multimídia: um estudo de caso com o ToolBook Instructor. In RENOTE Volume 4, número 1. 2006

[27] SimCity. SimCity. 2014, Disponível em: http://www.simcity.com/en_US/faq, acesso em 24 set. 2014.

[28] M. M. Souza, R. F. Resende, L. S. Prado, E. F. Fonseca, F. A. Carvalho e A. D. Rodrigues. SPARSE: Um Ambiente de Ensino e Aprendizado de Engenharia de Software Baseado em Jogos e Simulação. In: Simpósio Brasileiro de Informática na Educação. 2010.

[29] S. M. P. Santos. A ludicidade como ciência. Editora Vozes, Volume 1. 2001

[30] B. J. Duch, S. E. Groh, D. E. Allen. Why Problem-Based Learning?. The Power of ProblemBased Learning. Stylus Publishing. 2001

[31] G. T. A. Guedes. UML 2: Uma Abordagem Prática. Editora Novatec, 2a edição, 2011. 